\title{
Chronic stress alters neuropeptide $Y$ signaling in the bed nucleus of the stria terminalis in DBA/2J but not C57BL/6J mice
}

\author{
Kristen E. Pleil, Alberto Lopez, Nora McCall, Ana M. Jijon, Jose Peña Bravo, and Thomas L. \\ Kash \\ Bowles Center for Alcohol Studies and Department of Pharmacology, School of Medicine, \\ University of North Carolina Chapel Hill, Chapel Hill, NC 27599, USA
}

\begin{abstract}
Numerous rodent and human studies have demonstrated that neuropeptide Y (NPY) is involved in the regulation of anxiety-related behaviors. In this study, we examined whether there were differences in NPY signaling between two inbred mouse strains (C57BL/6J and DBA/2J) that exhibit divergent basal and stress-induced anxiety phenotypes. We focused on the bed nucleus of the stria terminals (BNST), a structure in the extended amygdala that is important for the regulation of anxiety-like behavior and contains NPY receptors. While results from whole-cell voltage-clamp recordings and immunofluorescence histochemistry revealed no significant basal differences in NPY signaling or NPY and NPY Y2 receptor (Y2R) expression in the BNST, these measures were differentially altered by chronic restraint stress. Ten days of chronic restraint stress increased basal GABAergic transmission and decreased NPY's ability to inhibit evoked GABAergic transmission in the dorsolateral BNST (dlBNST) via Y2R in DBA/2J, but not C57BL/6J, mice. Additionally, restraint stress increased NPY and Y2R expression across subregions of the BNST of DBA/2J mice 24 hrs after the last stress exposure, but no changes were observed in C57BL/6J mice. Together, these results suggest that chronic restraint stress engages the NPY system and alters NPY modulation of inhibitory transmission in the dlBNST of DBA/2J mice, but not C57BL/6J mice, which may be related to increased expression of anxiety-related behaviors in this strain.
\end{abstract}

\section{Keywords}

chronic stress; extended amygdala; NPY; inhibition; GABA

\section{Introduction}

Exposure to stress is a major risk factor for various neuropsychiatric diseases, including post-traumatic stress disorder (PTSD) and anxiety disorders. It has been hypothesized that repeated exposure to stress can alter the balance of neural stress (e.g., corticotrophinreleasing factor (CRF)) and anti-stress (e.g., neuropeptide Y (NPY)) systems in circuitry involved in the regulation of emotional behavior, leading to changes in the expression of affective behaviors, such as depression and anxiety (Thorsell, 2010). NPY and its primary receptors, Y1R and Y2R, are highly expressed in regions throughout the central nervous

\footnotetext{
(C) 2011 Elsevier Ltd. All rights reserved.

Publisher's Disclaimer: This is a PDF file of an unedited manuscript that has been accepted for publication. As a service to our customers we are providing this early version of the manuscript. The manuscript will undergo copyediting, typesetting, and review of the resulting proof before it is published in its final citable form. Please note that during the production process errors may be discovered which could affect the content, and all legal disclaimers that apply to the journal pertain.
} 
system that are implicated in the regulation of affective behavior (Parker and Herzog, 1999). NPY serves as a buffer against stress-induced alterations in behavior, and several studies in humans have demonstrated correlations between plasma NPY levels and PTSD (Rasmusson et al., 2000; Sah et al., 2009; Yehuda et al., 2005). A large literature in rodents indicates that both genetic and pharmacological manipulations of NPY and its receptors lead to significant alterations in anxiety, depression, and stress responsivity (e.g., Heilig, 2004). For example, genetic deletion of NPY produces anxiogenesis (Bannon et al., 2000), while systemic administration of NPY produces anxiolysis (Heilig et al., 1989). Consistent with these studies, different inbred strains of mice that exhibit divergent basal anxiety phenotypes also display different levels of NPY expression in associated brain regions (e.g., Misra and Pandey, 2003).

Genetics appear to play a large role in determining an individual's susceptibility to developing stress-induced behavioral pathologies. Several recent studies have shown that there is great variability in the development of PTSD among individuals exposed to the same type of combat stress (Seal et al., 2009), and polymorphisms in the NPY gene are related to stress sensitivity in humans (Mickey et al., 2011; Zhou et al., 2008). This genetic influence on stress-responsivity is apparent in animal models as well. For example, chronic stress can produce divergent behavioral phenotypes in different inbred strains of mice. In response to repeated restraint stress, DBA/2J mice develop an anxiogenic phenotype, whereas C57BL/6J mice display an anxiolytic phenotype (e.g., Mozhui et al., 2010). However, while the anxiety-like phenotype of Y2R knockout (KO) mice depends on background strain (Zambello et al., 2010), it is unclear if altered NPY signaling plays a role in the behavioral differences observed in C57BL/6J and DBA/2J mice.

One particularly important brain region for the anti-stress actions of NPY is the extended amygdala, the primary output structure of the amygdala, comprised of the central nucleus of the amygdala (CeA) and the bed nucleus of the stria terminalis (BNST) (McElligott and Winder, 2009). The BNST receives inputs from cortical and limbic structures, including a dense GABAergic projection from the $\mathrm{CeA}$, and projects to brain regions directly involved in the production of anxiety-related behaviors. A recent report demonstrated that there is a NPY Y2 receptor (Y2R)-containing GABA projection from the CeA to the BNST (Tasan et al., 2010). Further, the authors showed that removal of $Y 2 R$ from the CeA lead to reductions in both Y2R binding in the BNST and reductions in anxiety-like and depression-like behavior, suggesting that Y2R in the BNST plays a key role in regulation of affective behavior (Tasan et al., 2010). Interestingly, NPY modulates GABAergic transmission in the BNST. For example, bath application of NPY during electrophysiological recording of BNST neurons in an ex vivo slice preparation decreases GABA release via activation of presynaptic Y2R (Kash and Winder, 2006). However, little is known about the ability of repeated stress to alter NPY signaling in the BNST. The current study used C57BL/6J mice as a model for resilience to chronic stress and DBA/2J mice as a model for susceptibility to stress-induced anxiety to examine whether these two strains differ in basal NPY signaling and in sensitivity of the NPY signaling system to chronic restraint stress, which we previously showed produces opposite anxiety phenotypes in these strains (Mozhui et al., 2010).

\section{Methods}

\subsection{Subjects}

Adult male C57BL/6J and DBA/2J (6-9 weeks old, Jackson Laboratories) were grouphoused in a colony room with 12:12 hr light-dark cycle with lights on at 7 a.m. Mice had ad libitum access to rodent chow and water. All procedures were approved by the Institutional Animal Care and Use Committee of the University of North Carolina at Chapel Hill and 
performed in accordance with the National Institutes of Health guide for the care and use of laboratory animals.

\subsection{Chronic restraint stress}

Mice were placed in ventilated $50 \mathrm{~mL}$ Falcon tubes for $2 \mathrm{hr} /$ day (10:00 a.m. - 12:00 p.m.) for 10 consecutive days, while naïve mice remained in their home cages. Twenty-four hours after the final stress exposure, mice were sacrificed and their brains harvested for fluorescence immunohistochemistry or slice electrophysiology.

\subsection{Brain slice preparation for electrophysiology}

Mice were decapitated under isoflurane anesthesia. Brains were rapidly removed and placed in ice-cold sucrose-artificial cerebrospinal fluid (ACSF): (in mM) 194 sucrose, $20 \mathrm{NaCl}, 4.4$ $\mathrm{KCl}, 2 \mathrm{CaCl}_{2}, 1 \mathrm{MgCl}_{2}, 1.2 \mathrm{NaH}_{2} \mathrm{PO}_{4}, 10.0$ glucose, and $26.0 \mathrm{NaHCO}_{3}$ saturated with $95 \%$ $\mathrm{O}_{2} / 5 \% \mathrm{CO}_{2}$. Coronal slices $300 \mu \mathrm{m}$ in thickness containing the dorsal BNST (Bregma 0.26$0.02 \mathrm{~mm}$ ) were identified using the internal capsule, anterior commissure, and stria terminalis as landmarks, according to the Allen mouse brain atlas, and prepared using a Leica VT1200 vibratome. Slices were stored in a heated (approximately $28{ }^{\circ} \mathrm{C}$ ), oxygenated holding chamber containing ACSF [(in mM) $124 \mathrm{NaCl}, 4.4 \mathrm{KCl}, 2 \mathrm{CaCl}_{2}, 1.2 \mathrm{MgSO}_{4}, 1$ $\mathrm{NaH}_{2} \mathrm{PO}_{4}, 10.0$ glucose, and $26.0 \mathrm{NaHCO}_{3}$ ]. Slices were transferred to a submerged recording chamber (Warner Instruments, Hamden, CT), where they were perfused with heated, oxygenated ACSF at a rate of approximately $2 \mathrm{ml} / \mathrm{min}$ and allowed to equilibrate for $30 \mathrm{~min}$ before electrophysiological recordings.

\subsection{Whole-cell voltage-clamp recordings}

We performed our electrophysiological recordings on neurons throughout the dorsolateral BNST (dlBNST), a particularly important area for the actions of corticotrophin-releasing factor (CRF) related to stress and anxiety (Huang et al., 2010). Because specific subnuceli of the dIBNST cannot be anatomically distinguished in this preparation (especially the oval nucleus), we performed our electrophysiological recordings on neurons throughout the dIBNST. Neurons were directly visualized with infrared video microscopy (Olympus). Recording electrodes (3-5 M $\Omega$ ) were pulled with a Flaming-Brown Micropipette Puller (Sutter Instruments, Novato, CA) using thin-walled borosilicate glass capillaries. Electrodes were filled with (in $\mathrm{mM}$ ) $70 \mathrm{KCl}, 65 \mathrm{~K}^{+}$-gluconate, $5 \mathrm{NaCl}, 10 \mathrm{HEPES}, 2 \mathrm{QX}-314,0.6$ EGTA, 4 ATP, 0.4 GTP, pH 7.2, 290-295 mOsmol. Spontaneous and evoked GABA type A $\left(\mathrm{GABA}_{\mathrm{A}} \mathrm{R}\right)$-mediated inhibitory postsynaptic currents (IPSCs) were pharmacologically isolated during all electrophysiological recordings by adding $3 \mathrm{mM}$ kynurenic acid to block AMPA and NMDA receptor-dependent postsynaptic currents (Ascent Scientific, Princeton, NJ). Signals were acquired via a Multiclamp 700B amplifier (Molecular Devices, Sunnyvale, CA), digitized at $10 \mathrm{kHz}$, and analyzed using Clampfit 10.2 software (Molecular Devices, Sunnyvale, CA).

After entering a whole-cell configuration, cells were held at $-70 \mathrm{mV}$, and initial membrane capacitance and resistance were noted. Immediately following, an IV plot with $1210-\mathrm{mV}$ steps beginning at $-140 \mathrm{mV}$ was recorded in order to determine the presence and magnitude of a hyperpolarization-activated current (Ih). After allowing the neuron to rest at $-70 \mathrm{mV}$ for several minutes, spontaneous IPSCs (sIPSCs) were recorded at a holding voltage of -70 $\mathrm{mV}$ for $120 \mathrm{~s}$ to determine the amplitude and frequency of these spontaneous inhibitory events. For evoked inhibitory postsynaptic currents (eIPSCs), twisted nichrome wire stimulating electrodes were placed dorsal to the recording electrode, $100-500 \mu \mathrm{m}$ medial from the recorded neuron. IPSCs were evoked at $0.1 \mathrm{~Hz}$ by local fiber stimulation with bipolar electrodes (5-50 V with a $100-150 \mu$ s duration). After at least five minutes in which mean peak evoked IPSC (eIPSC) amplitude was stable ("baseline period"), drugs mixed in 
distilled water or dimethyl sulfoxide and diluted to appropriate concentrations in the bath solution (ACSF with $3 \mathrm{mM}$ kynurenic acid) were applied to the bath for 10 minutes, followed by a five-minute washout period. eIPSC experiments were analyzed by measuring the peak amplitude of the synaptic response, which was normalized to the baseline period. Input resistance and access resistance were continuously monitored during all experiments, and those in which changes in access resistance were greater than $20 \%$ were not included in the data analysis. In addition, cells that had a membrane capacitance and Ih current magnitude greater than one standard deviation above the group mean were excluded from analysis (one cell per group), because these may represent a small, uncharacterized subpopulation of neurons that respond to NPY in the opposite fashion of other neurons in the dIBNST. Enough of these cells could not be found in order to characterize their response to include in the analyses.

\subsection{Fluorescence immunohistochemistry}

Mice were anesthetized using Avertin and perfused transcardially with chilled PBS, followed by a $4 \%$ paraformaldehyde solution. Brains were post-fixed with $4 \%$ paraformaldehyde for 24 hours and immersed in a sucrose solution for a minimum of 24 hours until slices were collected. Brains were hemisected and coronal slices $45 \mu \mathrm{m}$ in thickness containing the BNST were prepared using a Leica VT1200 vibratome (Leica Microsystems, Nussloch, Germany). One hemisphere of each brain was used for NPY-IR and the other for Y2R-IR, and this was randomly selected and counterbalanced within each group of mice. Because 6-8 slices were used for immunohistochemistry per subject for each type of stain, all brains could not be processed at the same time. Thus, examination of basal differences between C57BL/6J and DBA/2J mice were assessed first and separately from the effects of stress within each strain. For examination of the effects of chronic stress on NPY and Y2R expression within each strain, C57BL/6J and DBA/2J brains were processed and imaged separately to ensure a complete and meaningful analysis void of inter-run variability.

All slices containing the BNST were first rinsed in PBS three times for 10 min, incubated in $50 \%$ methanol for $30 \mathrm{~min}$ and then $3 \%$ hydrogen peroxide for $5 \mathrm{~min}$ to quench endogenous peroxidases, and then rinsed in PBS three more times. Slices used for NPY-IR were incubated in PBS containing 0.5\% Triton X-100 for 30 min, rinsed with PBS for $10 \mathrm{~min}$, and incubated in a blocking solution of PBS containing $0.1 \%$ Triton X-100 and 10\% normal donkey serum for $60 \mathrm{~min}$. Slices were then directly transferred to the blocking solution also containing a 1:1,250 concentration of anti-NPY (Abcam) for $48 \mathrm{hrs}$ at $4^{\circ} \mathrm{C}$. Slices were rinsed with PBS four times, incubated in a secondary solution containing Cy2 (1:200) for 2 hrs at RT, and rinsed in PBS four times.

Because Y2R-IR is less easily detected, slices used for Y2R immunohistochemistry underwent an amplification procedure using a Tyramide Signal Amplfication (TSA) detection kit (Jackson Laboratories) to increase signal sensitivity. While it should be noted that there is a possibility that TSA amplification may not be linear and thus may indicate larger differences in protein signal than are actually present, this amplification procedure is commonly used for low signal antibodies, including the Y2R antibody used here (e.g., Stanic et al., 2006). This antibody has been shown to be selective, as there is an absence of all staining in the Y2R KO mouse (Stanic et al., 2006). Slices were incubated in primary solution containing $0.3 \%$ Triton $\mathrm{X}-100,0.5 \%$ bovine serum albumin, and a 1:3,000 concentration of anti-Y2R (Neuromics, Edina, $\mathrm{MN}$ ) for $24 \mathrm{hrs}$ at $4^{\circ} \mathrm{C}$. Slices were washed in TNT buffer solution containing Tris/ $\mathrm{HCl}, \mathrm{NaCl}$, and Tween 20 for 10 minutes followed by TNB blocking solution containing TNT buffer with $0.5 \%$ blocking reagent provided in the TSA kit for 30 minutes (as described in TSA kit manual). Slices were then washed in TNB solution containing horseradish peroxidase (1:200) for 30 minutes and rinsed in TNT buffer four times (five minutes each). Sections were incubated in Cy3 (1:50) in amplification 
diluents provided in the TSA kit for 10 minutes and then rinsed in TNT buffer two times (10 minutes each). All slices were mounted on glass slides, air-dried, and coverslipped. Images of NPY-IR and Y2R-IR in the BNST were obtained with a Leica SP2 upright confocal microscope with 10X objective and Leica Confocal Software.

All serial sections throughout the BNST (6-8 per hemisphere) were used for quantification of NPY-IR and Y2R-IR by a researcher blind to experimental conditions using Image $\mathbf{J}$ Software (Image J, National Institute of Health, Bethesda, MD). The experimenter drew a contour around each subregion of BNST to be analyzed (oval, dorsal non-oval, and ventral), as illustrated for NPY-IR in Figure 1. We elected to analyze these specific subregions because they have distinct inputs (Dong et al., 2001). From our images and other published images (Stanic et al., 2006), it was clear that the oval nucleus had a qualitatively smaller signal. The intensity value was obtained by calculating the percent of the total area studied that shows staining relative to sub-threshold background. The size of the area was held constant between animals and groups for each subregion. Intensity values for all serial sections for each mouse were averaged to obtain one value per mouse for each subregion of the BNST analyzed.

\subsection{Statistical analysis}

Appropriate statistical analyses were performed using Graphpad Prism. Basal strain differences in NPY-IR and Y2R-IR were evaluated using unpaired t-tests between strains, and basal strain differences in NPY signaling were examined using $2 \times 2$ analysis of variance (ANOVA). Effects of chronic stress on NPY-IR, Y2R-IR, and NPY's ability to modulate evoked IPSC amplitude were determined using unpaired t-tests between conditions within each strain, as initial experiments showed that there were no differences between C57BL/6J and DBA/2J control subject values for any of these measures, and because C57BL/6J and DBA/2J brains had to be processed for immunohistochemistry separately due to the large number of slices in each group. When variances were significantly different between groups for t-tests, Welch's correction was employed in order to maintain a conservative interpretation of the results. Effects of drugs and chronic stress during electrophysiological recordings were evaluated via t-tests between groups during the washout period or between baseline and washout periods. All values given for IR and drug effects are presented as mean \pm S.E.M.

\section{Results}

\subsection{No basal strain differences in NPY signaling}

3.1.1 Slice electrophysiology-Prior research has shown that NPY inhibits GABAergic transmission in the ventral BNST (vBNST) of C57BL/6J mice via Y2R (Kash and Winder, 2006). Here we show for the first time that NPY decreases GABAergic transmission in the dlBNST via Y2R in both C57BL/6J and DBA/2J mice (Figure 2). Pre-bathing brain slices in the Y2R antagonist BIIE 0246, but not the Y1R antagonist BIBP 3226 (both drugs $1 \mu \mathrm{M}$; Tocris Bioscience, Ellisville, MO), for at least 10 min prior to application of NPY significantly and similarly blunted NPY's ability to inhibit GABAergic transmission in the dlBNST of both C57BL/6J (Figure 2A and C) and DBA/2J (Figure 2B and D) mouse strains. This was demonstrated by a $2 \times 2$ ANOVA that revealed a main effect of drug $(\mathrm{F}(1,14)=38.4, \mathrm{p}<0.001)$ but no effect of strain or interaction (p's < 0.45). Post-hoc comparisons within each strain confirmed the ability of the $\mathrm{Y} 2 \mathrm{R}$, but not $\mathrm{Y} 1 \mathrm{R}$, antagonist to block the NPY effect (C57BL/6J: Figure 2C, BIBP 3226: 37.4\% \pm 7.1\%, BIIE 0246: 6.2\% \pm $7.1 \%, \mathrm{t}(7)=3.70, \mathrm{p}=0.008$; DBA/2J: Figure 2D, BIBP 3226: $41.5 \% \pm 5.9 \%$, BIIE 0246: $2.3 \% \pm 6.5 \%, \mathrm{t}(7)=5.64, \mathrm{p}<0.001)$. 
3.1.2 Fluorescence immunohistochemistry-Because we found no differences in the ability of NPY to modulate GABAergic transmission in the dIBNST of either strain, and this modulation appeared to be completely dependent on activation of the $\mathrm{Y} 2 \mathrm{R}$, we next evaluated the expression of NPY and Y2R in the BNST of naïve C57BL/6J and DBA/2J mice, illustrated in Figure 3. We found no strain differences in NPY or Y2R expression in any BNST subregion (p's $>0.10$ ), with the exception of a trend for greater NPY expression in the oval nucleus of DBA/2J mice ( $p=0.052$; Figure 4$)$.

\subsection{Differential sensitivity to chronic restraint stress}

3.2.1 Slice electrophysiology-We found no basal differences between stress-resilient C57BL/6J and stress-susceptible DBA/2J mouse strains in NPY signaling in the dlBNST. Therefore, we next evaluated whether exposure to 2 hours of chronic restraint stress per day for 10 days altered basal properties of inhibitory transmission in the dlBNST. We found that sIPSC frequency was not altered by stress in C57BL/6J mice (Welch-corrected $\mathrm{t}(12)=0.45$, $\mathrm{p}>0.65$; Figure $5 \mathrm{~A}$ ) but was increased threefold in stressed DBA/2J mice compared to controls (Welch-corrected $\mathrm{t}(10)=4.20, \mathrm{p}=0.002$; Figure 5B). However, stress did not alter the amplitude of basal sIPSCs in either strain $(\mathrm{C} 57 \mathrm{BL} / 6 \mathrm{~J}$ : Welch-corrected $\mathrm{t}(12)=1.15, \mathrm{p}$ > 0.25 ; DBA/2J: Welch-corrected $\mathrm{t}(10)=1.19, \mathrm{p}>0.25$; Figure $5 \mathrm{C}$ and $\mathrm{D})$. Representative sIPSC average traces are presented in Figure 5E and F. The paired pulse ratio (PPR) of baseline eIPSC amplitude was also evaluated to examine presynaptic modulation. This was calculated by dividing the amplitude of the synaptic response to an electrical stimulation pulse by the amplitude of the synaptic response to an electrical pulse delivered $50 \mathrm{~ms}$ prior. Analysis of PPR revealed no effect of stress in either strain (C57BL/6J naïve: 1.05, stressed: $1.01 ; \mathrm{t}(15)=0.34, \mathrm{p}>0.70 ; \mathrm{DBA} / 2 \mathrm{~J}$ : naïve: 1.18 , stressed: 1.28 ; Welch-corrected $\mathrm{t}(7)=$ $0.23, \mathrm{p}>0.80$; data not shown). And, basal PPR and sIPSC frequency were not correlated with one another for either strain of mouse.

We then examined whether chronic restraint stress could alter NPY signaling in the dIBNST. Chronic stress did not alter the ability of NPY to modulate GABAergic transmission in the dlBNST of C57BL/6J mice $(\mathrm{t}(15)=0.36, \mathrm{p}>0.70$; Figure 6A and $\mathrm{C}$ ) but significantly decreased this Y2R-mediated effect in DBA/2J mice $(\mathrm{t}(11)=2.55, \mathrm{p}=0.027$; Figure 6B and D), measured 24 hrs after the final exposure to stress, shown in Figure 6. Interestingly, pre-application of $1 \mu \mathrm{M}$ BIIE 0246 was able to fully block the blunted NPYmediated decrease in GABAergic transmission observed in stressed DBA/2J mice (\% inhibition by NPY $=-2.9 \% \pm 8.2 \%$; data not shown), just as it did in naïve mice.

We continued to evaluate the effect of chronic stress on NPY signaling by analyzing the change in the coefficient of variation (CV) and the PPR after bath application of NPY. The $\mathrm{CV}$ was calculated by dividing the standard deviation of the mean peak amplitude of the electrically-evoked synaptic response by the mean response. Compared to the baseline, there was an increase in CV after NPY application in naïve but not stressed C57BL/6J and DBA/ 2J mice (C57BL/6J naïve: $\mathrm{t}(9)=2.90, \mathrm{p}=0.018 ; \mathrm{C} 57 \mathrm{BL} / 6 \mathrm{~J}$ stressed: $\mathrm{t}(6)=1.25, \mathrm{p}>0.25$; DBA/2J naïve: $t(5)=2.54, p=0.05$; DBA/2J stressed: $t(6)=1.57, p>0.15$; Figure 7A and B). A similar pattern emerged in the change in PPR after NPY for C57BL/6J, but not DBA/ 2J mice (Figure 7C and D). PPR was increased in naïve but not stressed C57BL/6J mice after NPY application (C57BL/6J naïve: $\mathrm{t}(9)=2.93, \mathrm{p}=0.017$; C57BL/6J stressed: $\mathrm{t}(6)=$ $1.99, \mathrm{p}=0.09)$. PPR was unchanged in both groups of DBA/2J mice $(\mathrm{DBA} / 2 \mathrm{~J}$ naïve: $\mathrm{t}(5)=$ $1.34, \mathrm{p}>0.20$; DBA/2J stressed: $\mathrm{t}(6)=0.61, \mathrm{p}>0.55)$. These results agree with previous studies in the BNST demonstrating a presynaptic locus of action for NPY via Y2R (Kash and Winder, 2006), and they also indicate that chronic stress may have had some subtle effects on NPY modulation of GABAergic function in C57BL/6J mice. 
Because these results suggested that chronic stress may have engaged the endogenous NPY system prior to bath application of NPY (up to $24 \mathrm{hrs}$ after the final stress exposure), and this effect appeared to be entirely mediated via Y2R, we next examined the effect of bath application of $1 \mu \mathrm{M}$ BIIE 0246 alone on inhibitory transmission in the dlBNST at this same time point. We found that BIIE 0246 did not alter eIPSC peak amplitude in the dIBNST of naïve or stressed mice of either strain (C57BL/6J naïve: $t(4)=0.87, p>0.40$; C57BL/6J stressed: $\mathrm{t}(3)=0.59, \mathrm{p}>0.55$; DBA/2J naïve $: \mathrm{t}(6)=0.36, \mathrm{p}>0.35$; DBA/2J stressed: $\mathrm{t}(4)=$ $0.29, \mathrm{p}>0.25$; see Figure 8), nor were there any differences between stressed and naïve mice within each strain $(\mathrm{C} 57 \mathrm{BL} / 6 \mathrm{~J}: \mathrm{t}(7)=0.98, \mathrm{p}>0.35$; DBA/2J: $\mathrm{t}(10)=0.45, \mathrm{p}>0.65)$. Thus, while bath application of the Y2R antagonist BIIE 0246 blocked NPY's ability to inhibit GABAergic transmission, it did not alter GABAergic transmission itself, demonstrated in Figure 8.

3.2.2 Fluorescence immunohistochemistry-Because chronic restraint stress altered NPY signaling in the dlBNST of DBA/2J, but not C57BL/6J, mice, we evaluated whether this stress paradigm also differentially alters the expression of NPY and Y2R in subregions of the BNST in these two strains. While stress did not alter NPY expression in C57BL/6J mice (all p's $>0.20$ ), NPY expression was significantly or nearly significantly increased in all subregions analyzed in DBA/2J mice (oval: $20 \%, \mathrm{t}(18)=2.76, \mathrm{p}=0.013$; dorsal nonoval: $15 \%, \mathrm{t}(18)=2.04, \mathrm{p}=0.057$; ventral: $22 \%, \mathrm{t}(18)=2.73, \mathrm{p}=0.014)$, as illustrated in Figure 9 and quantified in Figure 10. Similar results were found for Y2R expression (C57BL/6J: all p's > 0.60; DBA/2J: oval: $32 \%, \mathrm{t}(15)=3.39, \mathrm{p}=0.004$; dorsal non-oval: $21 \%, \mathrm{t}(15)=2.12, \mathrm{p}=0.051$; ventral: $28 \%, \mathrm{t}(15)=3.08, \mathrm{p}=0.008)$, illustrated in Figure 11 and quantified in Figure 12. Notably, both NPY and Y2R protein expression were qualitatively lower in the oval nucleus than other subregions of the BNST, consistent with published findings from other groups (Stanic et al., 2006; Stanic et al., 2008).

\section{Discussion}

\subsection{Relationship between basal NPY signaling in the BNST and anxiety}

Numerous studies have demonstrated that there are basal differences in anxiety-like behavior in C57BL/6J and DBA/2J mice, with DBA/2J mice exhibiting high anxiety (Misra and Pandey, 2003; Mozhui et al., 2010). And, a large literature demonstrates the involvement of both NPY signaling and the BNST in the regulation of anxiety-related behaviors, however the relationship between NPY signaling specifically in the BNST and stress/anxiety behavior has received little attention (Hawley et al., 2010). Interestingly, a study from the Pandey group found that NPY levels in the nucleus accumbens shell, a component of the extended amygdala, are higher in DBA/2J mice than C57BL/6J mice (Misra and Pandey, 2003). This is similar to our finding of a strong trend for greater basal NPY levels in the oval nucleus of the BNST of DBA/2J mice, a site at which basal NPY and Y2R levels are relatively low compared to other subregions of the BNST. Together, our data and previous research suggest that greater NPY immunoreactivity in the extended amygdala is consistent with the display of an anxiogenic phenotype. However, it should be noted that it remains unclear whether increased immunoreactivity reflects an increase or decrease in NPY release, or increased transcription/translation of NPY. Regardless, certain extended amydalar regions may be very sensitive to endogenous NPY levels, such that the amount of NPY expression in these regions ultimately has a large impact on anxiety-related behavior. Thus, basal physiological differences in the NPY system may largely contribute to straindependent differences in stress reactivity (Misra and Pandey, 2003; Mozhui et al., 2010).

To date, the best information about a role of the NPY system specifically in the BNST comes from a conditional knockout study that used a viral approach to remove Y2R from the 
CeA (Tasan et al., 2010). They found that deletion of Y2R in the CeA led to reductions of Y2R binding in the BNST and reduced anxiety-like and depression-like behaviors. We found no basal differences in NPY modulation of GABAergic transmission in the BNST between stress-resilient C57BL/6J and stress-susceptible DBA/2J mice, potentially reflecting the lack of basal differences in Y2R in the BNST.

\subsection{Stress-induced alterations in NPY signaling in the BNST are strain-dependent}

Ten consecutive days of restraint stress produces an increase in spontaneous GABAergic transmission, an increase in NPY and Y2R protein expression, and a decrease in Y2Rmediated NPY-induced depression of evoked GABAergic transmission in DBA/2J mice in the BNST. The same chronic stress, however, did not alter these measures in C57BL/6J mice. These results are consistent with previous behavioral results that DBA/2J mice display increased anxiety but C57BL/6J mice display decreased anxiety, at the same time point after this chronic stress paradigm (Mozhui et al., 2010). Thus, the behaviorally stress-susceptible DBA/2J strain displays stress-induced alterations in Y2R-mediated NPY signaling in the BNST, while the behaviorally stress-resilient C57BL/6J mouse strain displays protection against this alteration.

The negative role of Y2R signaling in the BNST in regulation of these behaviors previously discussed is consistent with our results demonstrating increased Y2R expression in the BNST following repeated restraint in DBA/2J mice. However, the anxiolytic, potentially adaptive effect of chronic stress in C57BL/6J mice may not be related to alterations in NPY signaling in the BNST. It is possible that alterations in NPY signaling in other regions, such as the CeA, or in other peptide and hormonal systems (e.g., CRF, dynorphin), are involved in the stress-induced anxiolysis observed in C57BL/6J mice. However, the lack of alterations in NPY and Y2R expression and function in the BNST of C57BL/6J mice supports previous research that this stress model does not lead to increased anxiety (Mozhui et al., 2010).

Intriguingly, we found that while Y2R expression was increased in the BNST of stressed DBA/2J mice, the Y2R-mediated effect of NPY on GABAergic transmission was decreased. Given the upregulation of both NPY and Y2R protein, we reasoned that the reduced ability of NPY to inhibit GABA release was due to endogenous activation of Y2R. However, we did not find that bath application the Y2R antagonist BIIE 0246 altered this "baseline" GABAergic transmission. One possibility consistent with these results is that a prior engagement of $\mathrm{Y} 2 \mathrm{R}$ systems leads to a functional down-regulation of $\mathrm{Y} 2 \mathrm{R}$, which would be consistent with previous studies that show Y2R can become internalized following activation (Parker et al., 2008). Alternatively, it is possible that the function of other NPY receptors, such Y1R, were also altered after stress, countering the effects of Y2R. However, given that we found no evidence that Y1R was involved in NPY modulation of inhibitory synaptic transmission in the dlBNST, this possibility is unlikely.

\subsection{Sources of Y2R-containing NPY neurons}

Previously published research shows that NPY modulation of evoked GABAergic transmission in the vBNST occurs via local, presynaptic Y2Rs (Kash and Winder, 2006). Here, we replicated this Y2R-mediated effect in the dIBNST and showed that it is altered by stress in DBA/2J mice. As stated earlier, there is a dense GABAergic input to the BNST from the CeA that contains Y2R and is related to anxiety-like behavior (Tasan et al., 2010), implicating this CeA-BNST synapse in the effects of stress we observed in this study. Interestingly, while viral deletion of $\mathrm{Y} 2 \mathrm{R}$ from the CeA greatly reduced $\mathrm{Y} 2 \mathrm{R}$ binding in the BNST, it did not eliminate it. This suggests that there may be other sources of Y2Rcontaining neurons that terminate in the BNST. Tracing studies indicate that while the 
medial amygdala also projects to the BNST, these projections appear to be focused on the anteroventral BNST, excluding this possibility (Dong et al., 2001). The other potential source would be interneurons within the BNST that may release NPY and contain Y2R at axon terminals, as it was recently shown that the lateral portion of the BNST contains neurons that express Y2R (Stanic et al., 2006).

\subsection{Effect of stress on the balance of basal peptide signaling systems}

We found that there was increased basal spontaneous GABAergic transmission in the BNST of stressed DBA/2J mice, but no difference in the PPR. And, these two measures were not correlated with one another. There are several possible reasons for this. PPR provides information about release probability, while sIPSC frequency reflects release probability as well as the number of release sites. Thus, it is possible that this increase in sIPSC frequency may reflect increased GABA release sites or GABAergic synapses. Alternatively, it is possible that GABA release is enhanced in only a portion of the projections that are evoked when determining PPR. Finally, it is possible that our stimulation paradigm recruits a different population of presynaptic terminals than those observed when recording spontaneous transmission. This increase in transmission could reflect a number of different possibilities. The BNST receives a strong GABAergic input from the CeA, thus it is likely that this increase could reflect increased release at CeA synapses within the BNST. This input from the CeA contains both CRF and NPY projections; however, we are unable to differentiate the relative ratio of these inputs. We speculate that following stress exposure, there is an increase in the CRF component of this projection, consistent with the increase in anxiety-like behavior and decrease in the NPY component. This could also explain the reduced Y2R inhibitory effects, as it has been hypothesized that Y2R are localized on NPY, but not CRF, projections. Alternatively, it is possible that this increased GABA release is due to increased release of local BNST interneurons.

In C57BL/6J mice, stress did not alter the magnitude of NPY inhibition of GABA transmission. However, it did reduce the effect of NPY on CV and PPR observed in the naïve state. The underlying mechanism of this change is unclear, as there are no gross differences in either basal PPR or sIPSC frequency in this strain. One possibility is that chronic restraint stress causes subtle alterations in presynaptic machinery, such as expression of vesicle release proteins, as has been demonstrated in the hippocampus (Gao et al., 2006).

\subsection{Conclusions}

The current study demonstrates that repeated restraint leads to alterations in both NPY and GABA systems in the BNST of DBA/2J, but not C57BL/6J, mice. We speculate that these alterations underlie the increased anxiety-like behavior seen following stress in DBA/2J mice. These results support previous findings that suggest there is an interaction between the function of Y2R and genetic background (Zambello et al., 2010).

\section{References cited}

Bannon AW, Seda J, Carmouche M, Francis JM, Norman MH, Karbon B, McCaleb ML. Behavioral characterization of neuropeptide Y knockout mice. Brain Res. 2000; 868:79-87. [PubMed: 10841890]

Dong HW, Petrovich GD, Swanson LW. Topography of projections from amygdala to bed nuclei of the stria terminalis. Brain Res Brain Res Rev. 2001; 38:192-246. [PubMed: 11750933]

Gao Y, Bezchlibnyk YB, Sun X, Wang JF, McEwen BS, Young LT. Effects of restraint stress on the expression of proteins involved in synaptic vesicle exocytosis in the hippocampus. Neuroscience. 2006; 141:1139-1148. [PubMed: 16757120] 
Hawley DF, Bardi M, Everette AM, Higgins TJ, Tu KM, Kinsley CH, Lambert KG. Neurobiological constituents of active, passive, and variable coping strategies in rats: integration of regional brain neuropeptide Y levels and cardiovascular responses. Stress. 2010; 13:172-183. [PubMed: 20214438]

Heilig M. The NPY system in stress, anxiety and depression. Neuropeptides. 2004; 38:213-224. [PubMed: 15337373]

Heilig M, Soderpalm B, Engel JA, Widerlov E. Centrally administered neuropeptide Y (NPY) produces anxiolytic-like effects in animal anxiety models. Psychopharmacology (Berl). 1989; 98:524-529. [PubMed: 2570434]

Huang MM, Overstreet DH, Knapp DJ, Angel R, Wills TA, Navarro M, Rivier J, Vale W, Breese GR. Corticotropin-releasing factor (CRF) sensitization of ethanol withdrawal-induced anxiety-like behavior is brain site specific and mediated by CRF-1 receptors: relation to stress-induced sensitization. J Pharmacol Exp Ther. 2010; 332:298-307. [PubMed: 19843974]

Kash TL, Winder DG. Neuropeptide Y and corticotropin-releasing factor bi-directionally modulate inhibitory synaptic transmission in the bed nucleus of the stria terminalis. Neuropharmacology. 2006; 51:1013-1022. [PubMed: 16904135]

McElligott ZA, Winder DG. Modulation of glutamatergic synaptic transmission in the bed nucleus of the stria terminalis. Prog Neuropsychopharmacol Biol Psychiatry. 2009; 33:1329-1335. [PubMed: 19524008]

Mickey BJ, Zhou Z, Heitzeg MM, Heinz E, Hodgkinson CA, Hsu DT, Langenecker SA, Love TM, Pecina M, Shafir T, Stohler CS, Goldman D, Zubieta JK. Emotion processing, major depression, and functional genetic variation of neuropeptide Y. Arch Gen Psychiatry. 2011; 68:158-166. [PubMed: 21300944]

Misra K, Pandey SC. Differences in basal levels of CREB and NPY in nucleus accumbens regions between C57BL/6 and DBA/2 mice differing in inborn alcohol drinking behavior. J Neurosci Res. 2003; 74:967-975. [PubMed: 14648603]

Mozhui K, Karlsson RM, Kash TL, Ihne J, Norcross M, Patel S, Farrell MR, Hill EE, Graybeal C, Martin KP, Camp M, Fitzgerald PJ, Ciobanu DC, Sprengel R, Mishina M, Wellman CL, Winder DG, Williams RW, Holmes A. Strain differences in stress responsivity are associated with divergent amygdala gene expression and glutamate-mediated neuronal excitability. J Neurosci. 2010; 30:5357-5367. [PubMed: 20392957]

Parker RM, Herzog H. Regional distribution of Y-receptor subtype mRNAs in rat brain. Eur J Neurosci. 1999; 11:1431-1448. [PubMed: 10103138]

Parker SL, Parker MS, Wong YY, Sah R, Balasubramaniam A, Sallee F. Importance of a N-terminal aspartate in the internalization of the neuropeptide Y Y2 receptor. Eur J Pharmacol. 2008; 594:2631. [PubMed: 18700141]

Rasmusson AM, Hauger RL, Morgan CA, Bremner JD, Charney DS, Southwick SM. Low baseline and yohimbine-stimulated plasma neuropeptide Y (NPY) levels in combat-related PTSD. Biol Psychiatry. 2000; 47:526-539. [PubMed: 10715359]

Sah R, Ekhator NN, Strawn JR, Sallee FR, Baker DG, Horn PS, Geracioti TD Jr. Low cerebrospinal fluid neuropeptide Y concentrations in posttraumatic stress disorder. Biol Psychiatry. 2009; 66:705-707. [PubMed: 19576571]

Seal KH, Metzler TJ, Gima KS, Bertenthal D, Maguen S, Marmar CR. Trends and risk factors for mental health diagnoses among Iraq and Afghanistan veterans using Department of Veterans Affairs health care, 2002-2008. Am J Public Health. 2009; 99:1651-1658. [PubMed: 19608954]

Stanic D, Brumovsky P, Fetissov S, Shuster S, Herzog H, Hokfelt T. Characterization of neuropeptide Y2 receptor protein expression in the mouse brain. I. Distribution in cell bodies and nerve terminals. J Comp Neurol. 2006; 499:357-390. [PubMed: 16998904]

Stanic D, Paratcha G, Ledda F, Herzog H, Kopin AS, Hokfelt T. Peptidergic influences on proliferation, migration, and placement of neural progenitors in the adult mouse forebrain. Proc Natl Acad Sci U S A. 2008; 105:3610-3615. [PubMed: 18305161]

Tasan RO, Nguyen NK, Weger S, Sartori SB, Singewald N, Heilbronn R, Herzog H, Sperk G. The central and basolateral amygdala are critical sites of neuropeptide $\mathrm{Y} / \mathrm{Y} 2$ receptor-mediated regulation of anxiety and depression. J Neurosci. 2010; 30:6282-6290. [PubMed: 20445054] 
Thorsell A. Brain neuropeptide Y and corticotropin-releasing hormone in mediating stress and anxiety. Exp Biol Med (Maywood). 2010; 235:1163-1167. [PubMed: 20881320]

Yehuda R, Brand S, Yang RK. Plasma Neuropeptide Y Concentrations in Combat Exposed Veterans: Relationship to Trauma Exposure, Recovery from PTSD, and Coping. Biol Psychiatry. 2005; 59:660-663. [PubMed: 16325152]

Zambello E, Zanetti L, Hedou GF, Angelici O, Arban R, Tasan RO, Sperk G, Caberlotto L. Neuropeptide Y-Y2 receptor knockout mice: influence of genetic background on anxiety-related behaviors. Neuroscience. 2010; 176:420-430. [PubMed: 21055451]

Zhou Z, Zhu G, Hariri AR, Enoch MA, Scott D, Sinha R, Virkkunen M, Mash DC, Lipsky RH, Hu XZ, Hodgkinson CA, Xu K, Buzas B, Yuan Q, Shen PH, Ferrell RE, Manuck SB, Brown SM, Hauger RL, Stohler CS, Zubieta JK, Goldman D. Genetic variation in human NPY expression affects stress response and emotion. Nature. 2008; 452:997-1001. [PubMed: 18385673] 


\section{HIGHLIGHTS}

- Repeated restraint stress alters NPY and Y2R expression in BNST of DBA/2J but not C57BL/6J mice.

- Repeated restraint stress alters NPY modulation of GABA transmission in the BNST of DBA/2J mice.

- Changes in the NPY system may underlie aspects of the stress sensitivity of $\mathrm{DBA} / 2 \mathrm{~J}$ mice. 


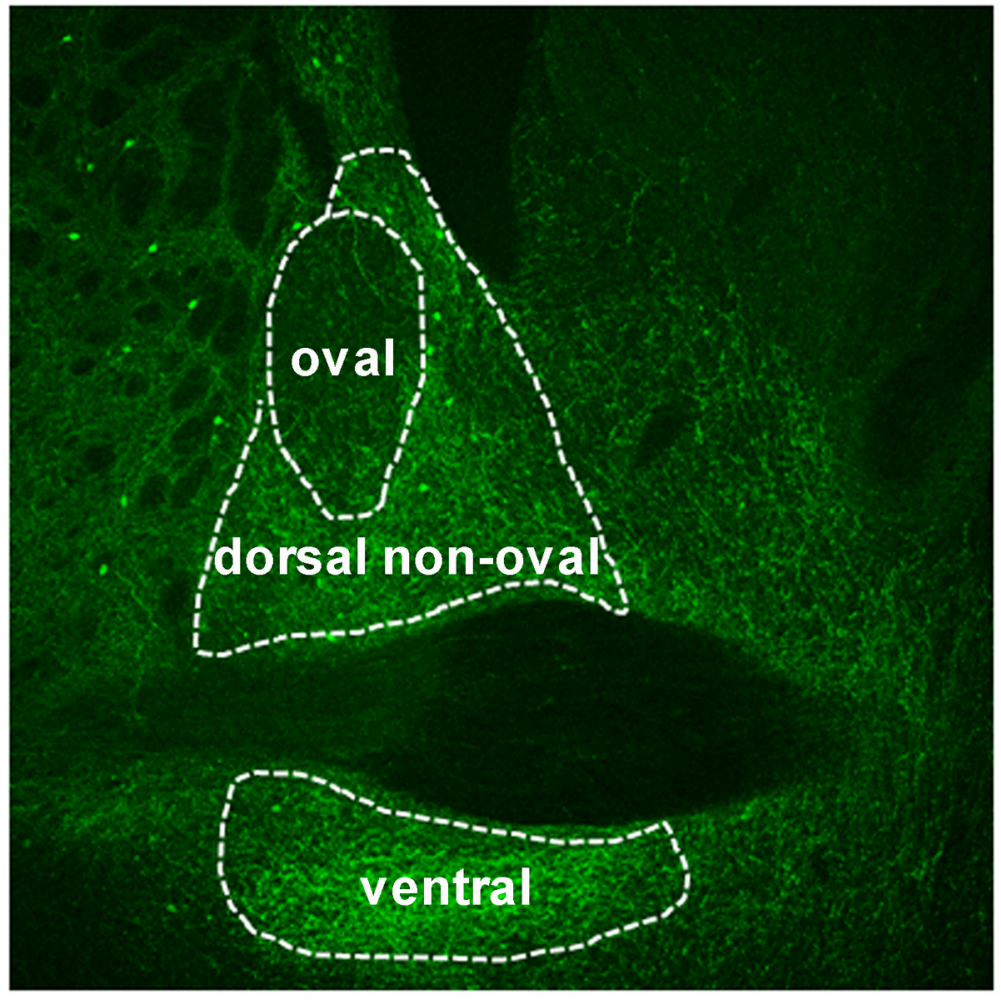

Figure 1.

Representative confocal image of the BNST delineating subregions in which IR was quantified. 

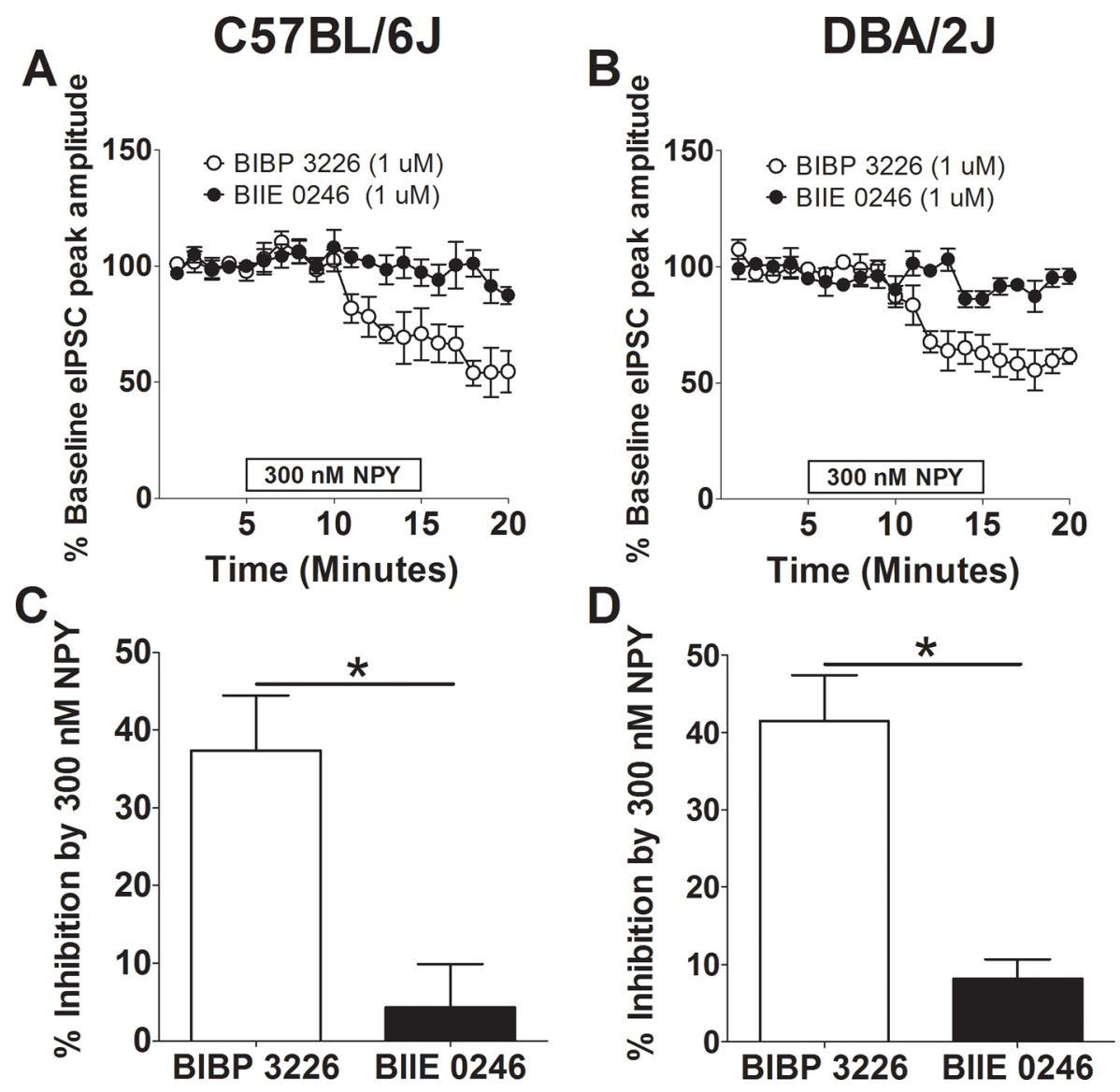

Figure 2.

A and B) Pooled data showing that pre-application of the Y2R antagonist BIIE $0246(1 \mu \mathrm{M})$, but not the Y1R antagonist BIBP $3226(1 \mu \mathrm{M})$, blocks the effect of bath application of NPY on the percent baseline eIPSC peak amplitude in the dlBNST of naïve C57B1/6J (A) and DBA/2J mice (B). C and D) Bar graphs illustrating that NPY-induced inhibition of

GABAergic transmission is significantly blunted by BIIE 0246 in C57BL/6J $(\mathrm{C} ; \mathrm{t}(7)=3.70$, $\mathrm{p}=0.008)$ and $\mathrm{DBA} / 2 \mathrm{~J}$ mice $(\mathrm{D} ; \mathrm{t}(7)=5.64, \mathrm{p}<0.001)$. 

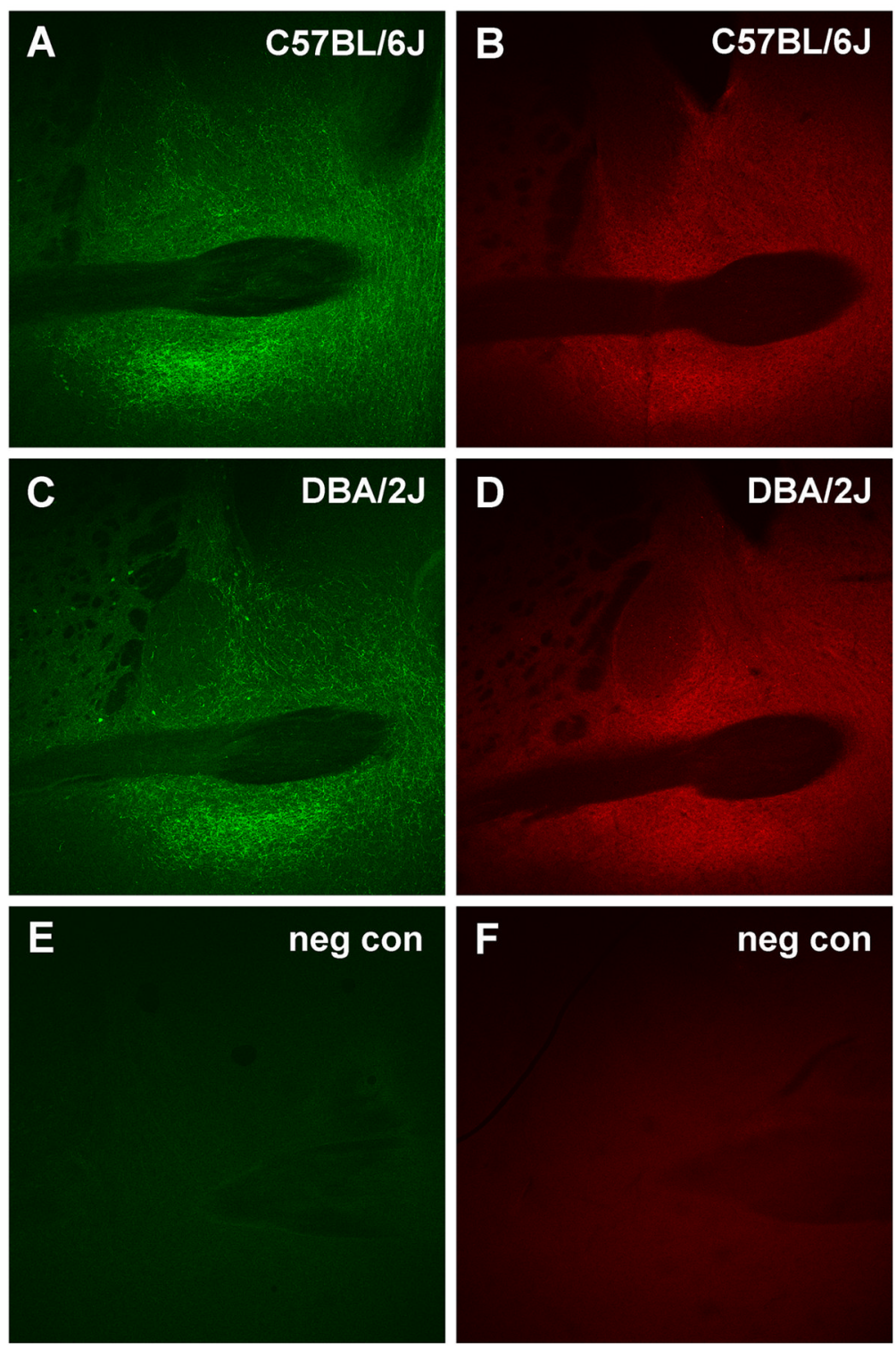

Figure 3.

A-D) Representative confocal images of NPY-IR (left column) and Y2R-IR (right column) in the BNST of naïve C57BL/6J (A and B) and DBA/2J mice (C and D). E and F) Tissue processed for immunohistochemistry without primary antibody solution to serve as negative controls. All images were taken with $10 \mathrm{X}$ objective. 
NPY-IR

Oval Nucleus

Y2R-IR
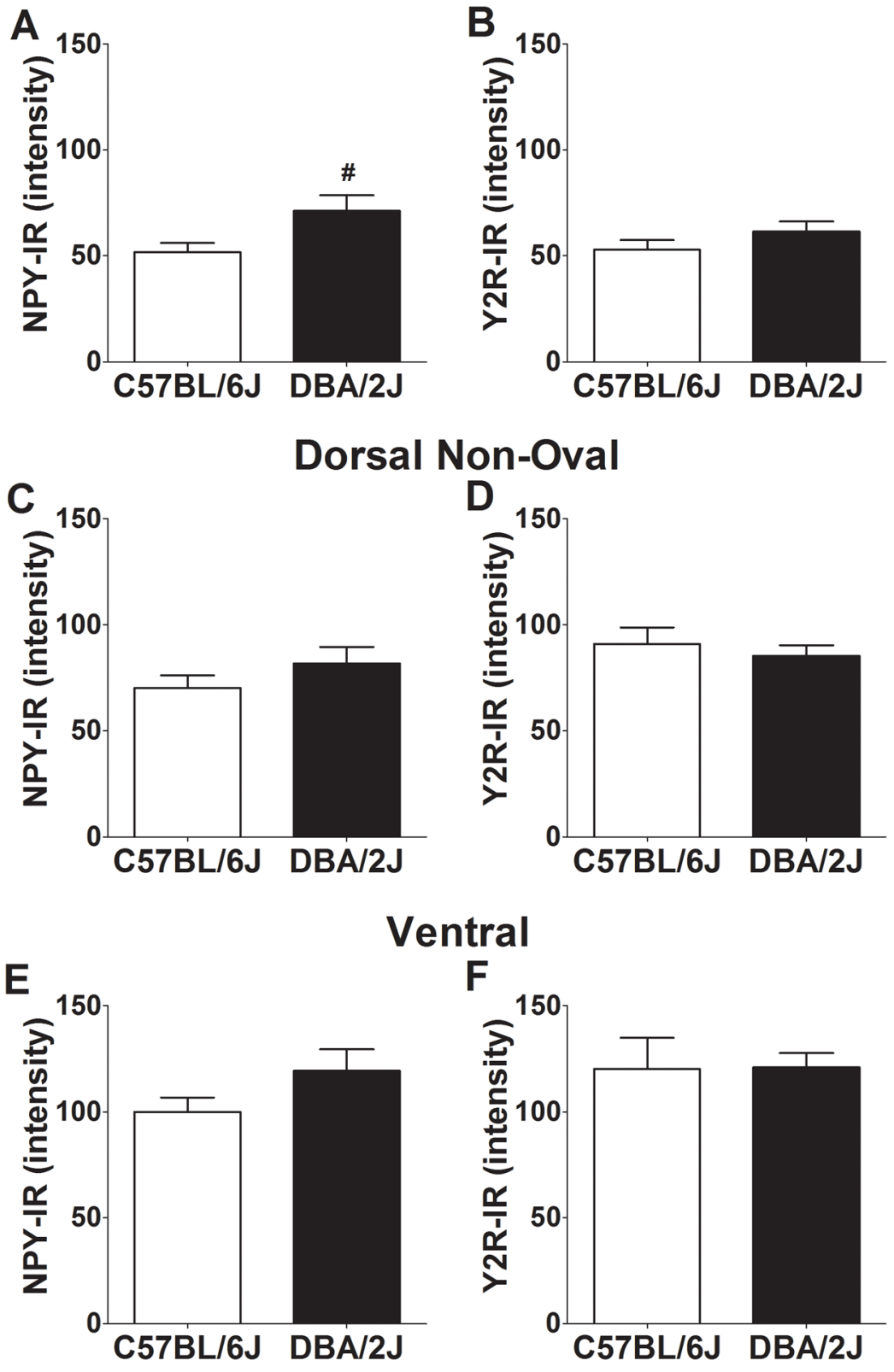

Figure 4.

Quantification of intensity values for NPY-IR (left column) and Y2R-IR (right column) in subregions of the BNST of C57BL/6J and DBA/2J mice, showing no differences between strains in protein expression, except a trend for greater NPY-IR in DBA/2J mice in the oval nucleus $(\mathrm{p}=0.052)$. 



Figure 5.

Basal inhibitory transmission in C57B1/6J (left column) and DBA/2J mice (right column) from whole-cell recordings in the dlBNST. While sIPSC frequency was not altered by chronic stress in C57BL/6J mice (A), it was increased three-fold in DBA/2J mice (Welchcorrected $\mathrm{t}(10)=4.20, \mathrm{p}=0.002)$. Stress did not alter the basal sIPSC amplitude in C57BL/ $6 \mathrm{~J}(\mathrm{C})$ or DBA/2J mice (D). Representative sIPSC traces are shown for C57BL/6J (E) and $\mathrm{DBA} / 2 \mathrm{~J}$ mice (F; scale bar dimensions are $500 \mathrm{~ms}$ and $20 \mathrm{pA}$, respectively). 
C57BL/6J
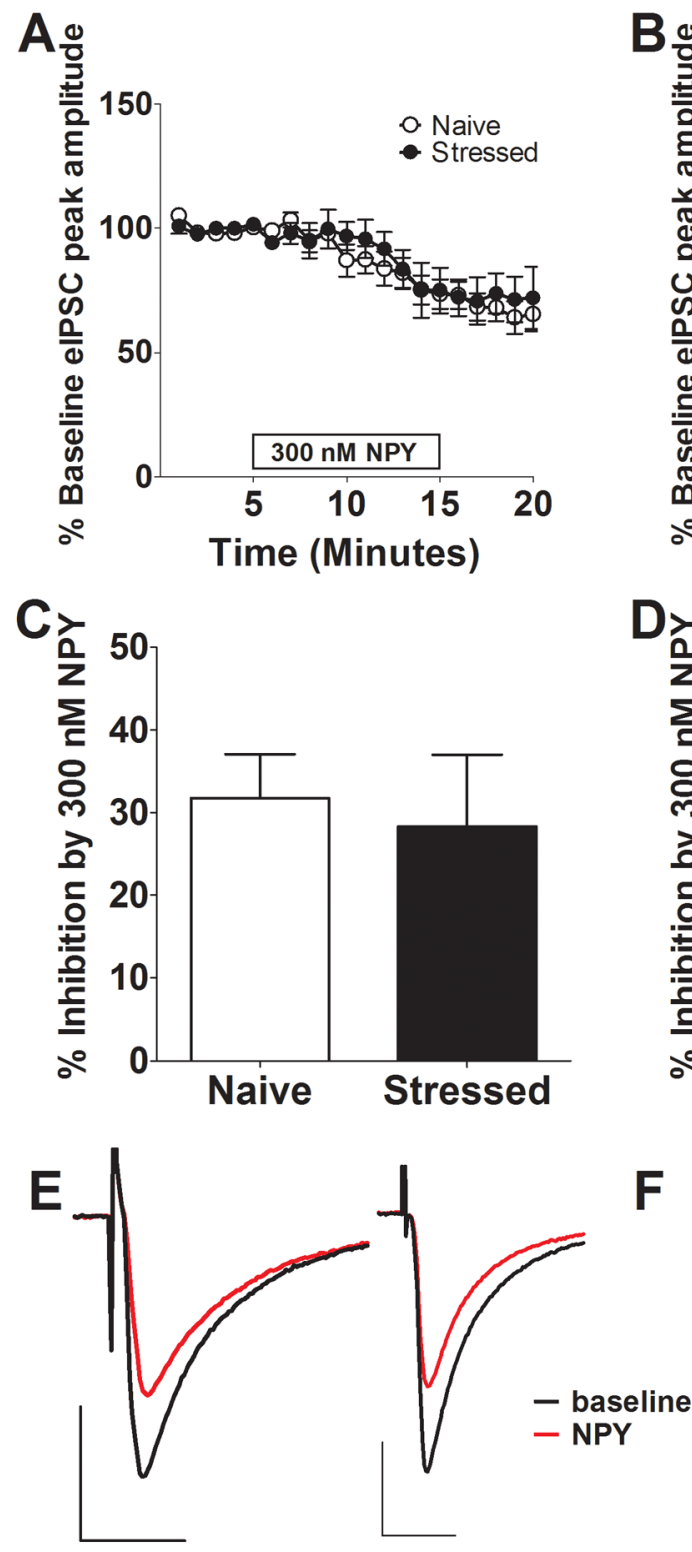

DBA/2J
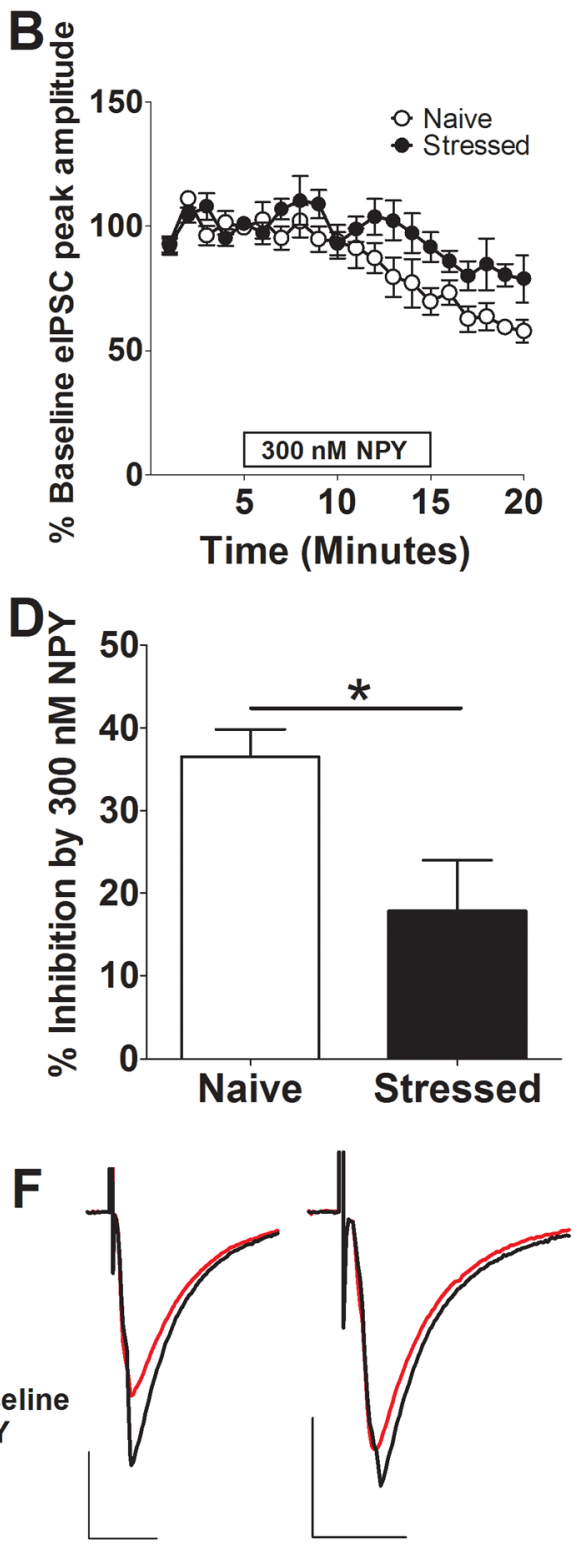

Figure 6.

A and B) Pooled data showing the effect of bath application of NPY on the percent baseline eIPSC peak amplitude in the dlBNST of naïve and chronically stressed C57B1/6J (A) and DBA/2J mice (B). C and D) Bar graphs illustrating that NPY-induced inhibition of GABAergic transmission is significantly blunted $24 \mathrm{hrs}$ after chronic restraint stress in $\mathrm{DBA} / 2 \mathrm{~J}(\mathrm{D} ; \mathrm{t}(11)=2.55, \mathrm{p}=0.027)$, but not C57BL/6J $(\mathrm{C})$, mice. $\mathrm{E}$ and F) Average representative eIPSC traces during $5 \mathrm{~min}$ baseline and washout periods illustrating the NPYinduced inhibition of eIPSC peak amplitude in naïve (E, left) and stressed (E, right) C57BL/ $6 \mathrm{~J}$ mice and naïve (F, left) and stressed (F, right) DBA/2J mice (scale bar dimensions are 20 $\mathrm{ms}$ and $100 \mathrm{pA}$, respectively). 


\section{C57BI/6J}


DBA/2J
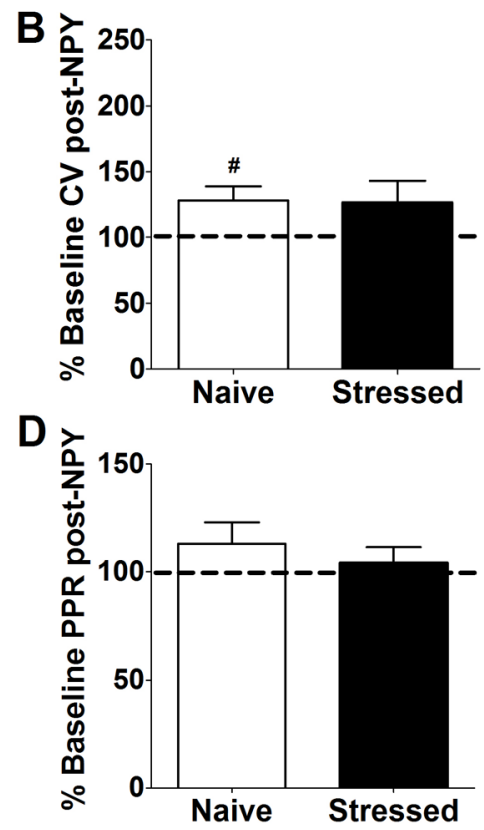

Figure 7.

The CV of eIPSC peak amplitude was increased after NPY application compared to baseline values in naïve $(\mathrm{t}(9)=2.90, \mathrm{p}=0.018)$ but not stressed $\mathrm{C} 57 \mathrm{~B} 1 / 6 \mathrm{~J}$ mice $(\mathrm{A})$, and a similar pattern was observed in DBA/2J mice $(B$; naïve: $t(5)=2.54, p=0.05)$. PPR of eIPSCs was increased in naïve $(\mathrm{t}(9)=2.93, \mathrm{p}=0.017)$ but not stressed C57BL/6J mice $(\mathrm{C})$, and no changes were observed in DBA/2J mice (D). 
C57BL/6J

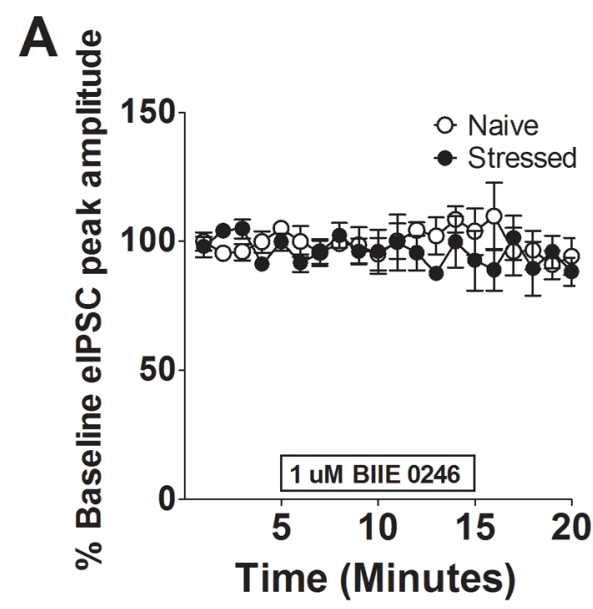

DBA/2J



Figure 8.

Pooled data showing that bath application of BIIE 0246 did not alter the percent baseline of eIPSC peak amplitude in the dlBNST of naïve and chronically stressed C57B1/6J (A) and DBA/2J mice (B). 

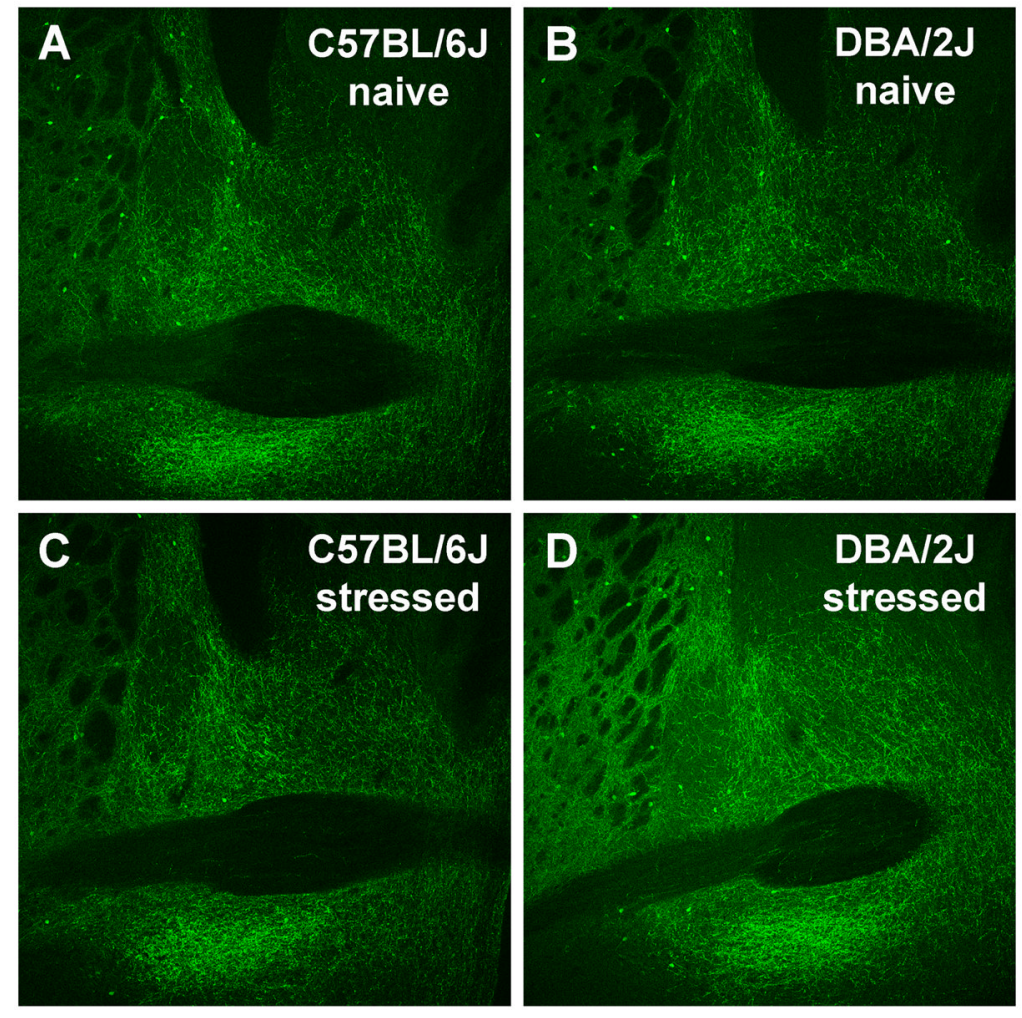

Figure 9.

Representative confocal images of NPY-IR in the BNST of naïve C57BL/6J (A) and DBA/ 2J mice (B), and stressed C57BL/6J (C) and DBA/2J mice (D) 24 hrs after 10 consecutive days of restraint stress, taken with $10 \mathrm{X}$ objective. 
C57BL/6J

DBA/2J

\section{Oval Nucleus}

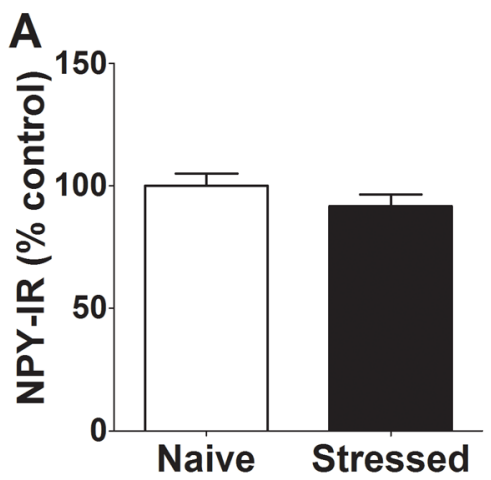

B



C

Dorsal Non-Oval
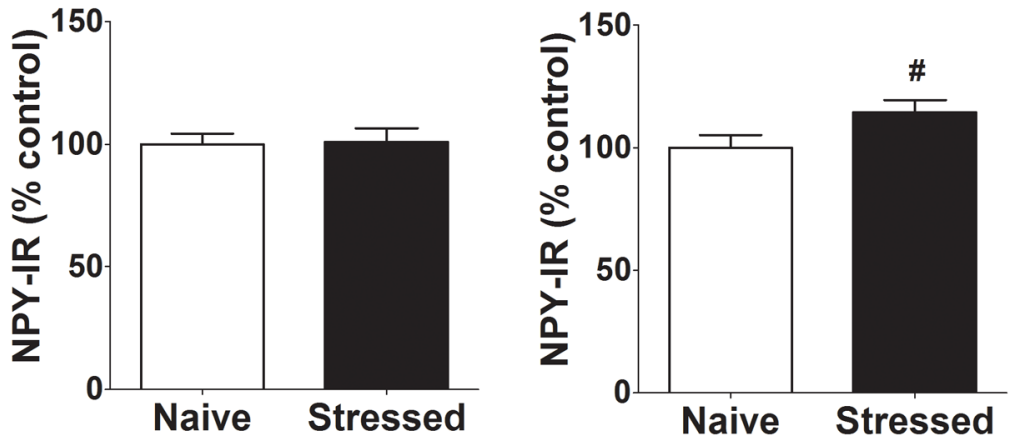

Ventral

E

$F$
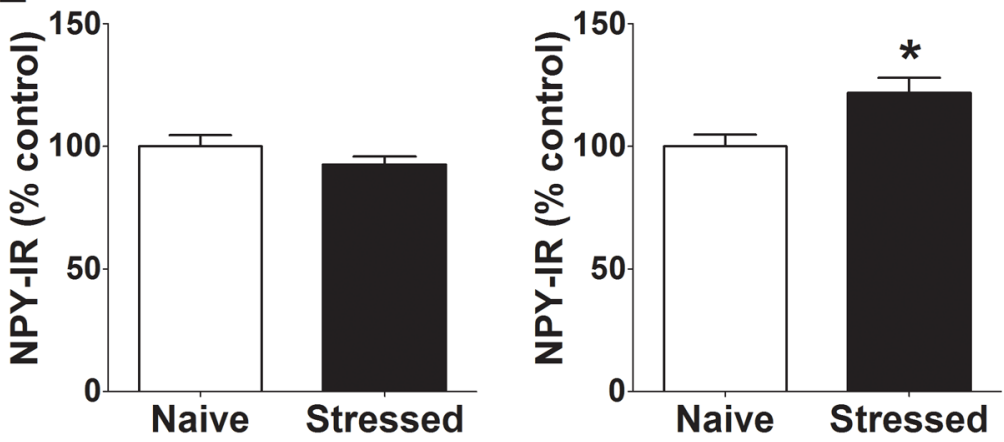

Figure 10.

Quantification of NPY-IR in subregions of the BNST of C57BL/6J (left column) and DBA/ $2 \mathrm{~J}$ mice (right column), presented as a percent of the average naïve values. Chronic stress increased NPY protein expression in DBA/2J mice in the oval $(\mathrm{B} ; 20 \%, \mathrm{t}(18)=2.76, \mathrm{p}=$ 0.013 ), dorsal non-oval $(\mathrm{D} ; 15 \%, \mathrm{t}(18)=2.04, \mathrm{p}=0.057)$, and ventral $(\mathrm{F} ; 22 \%, \mathrm{t}(18)=2.73$, $\mathrm{p}=0.014$ ) subregions. 

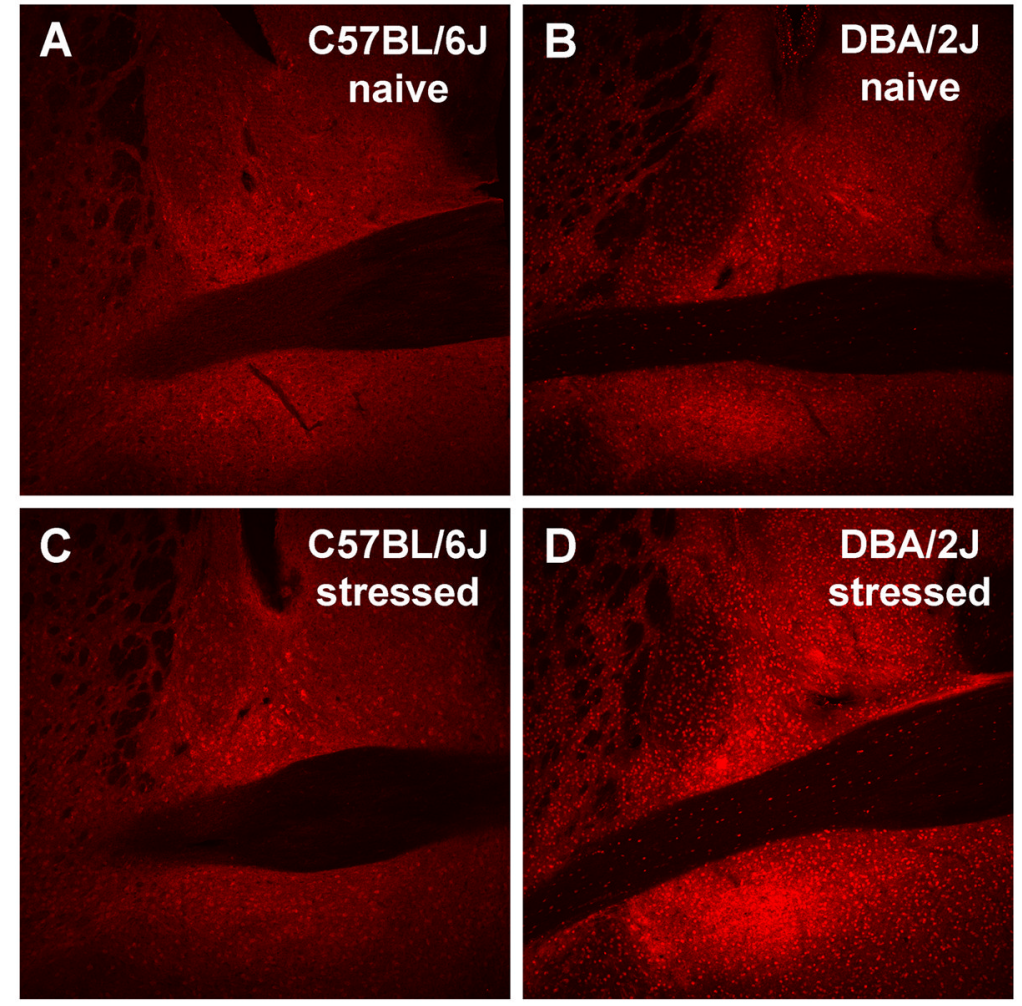

Figure 11.

Representative confocal images of Y2R-IR in the BNST of naïve C57BL/6J (A) and DBA/ 2J mice (B), and stressed C57BL/6J (C) and DBA/2J mice (D) 24 hrs after 10 consecutive days of restraint stress, taken with $10 \mathrm{X}$ objective. 


\section{C57BL/6J DBA/2J}

\section{Oval Nucleus}
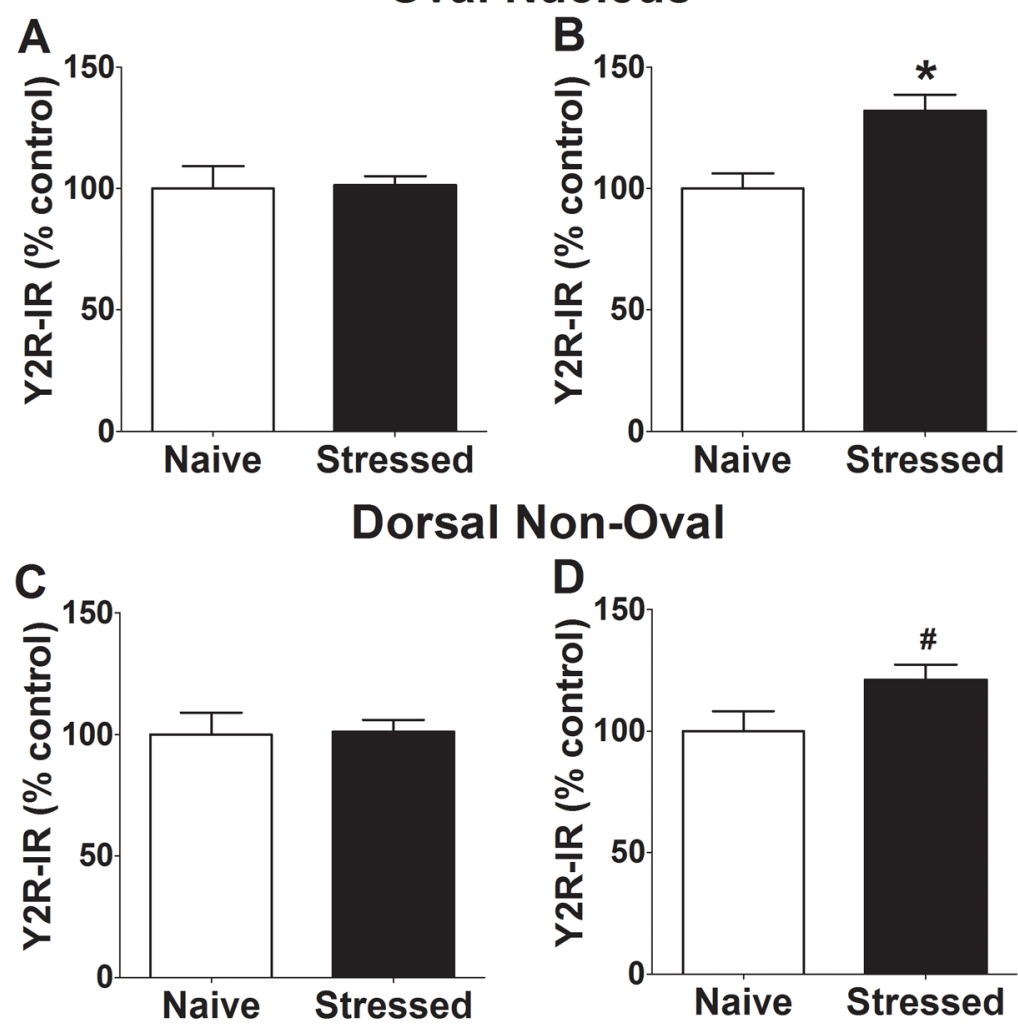

D

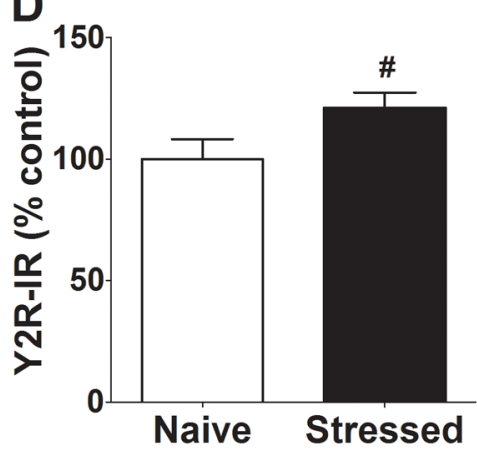

\section{Ventral}
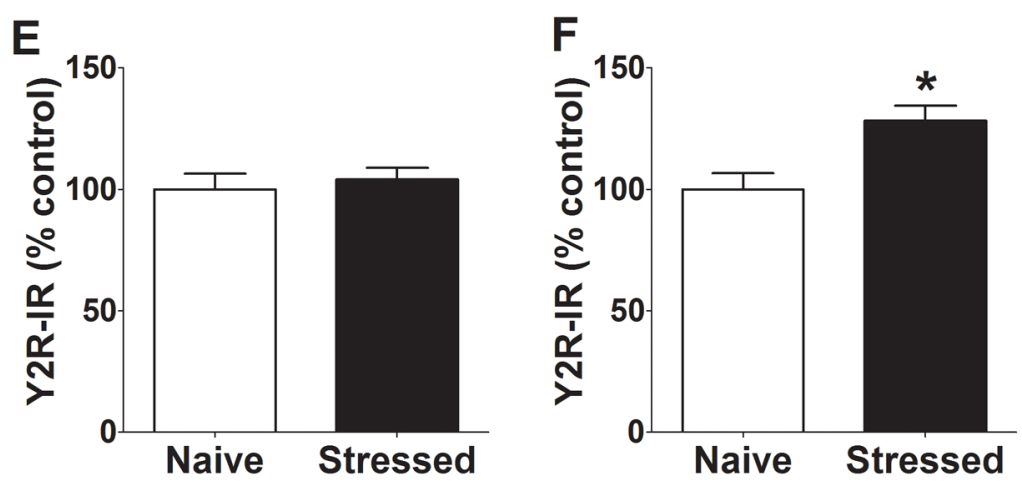

Figure 12.

Quantification of Y2R-IR in subregions of the BNST of C57BL/6J (left column) and DBA/ 2J mice (right column), presented as a percent of the average naïve values. Chronic stress increased Y2R protein expression in DBA/2J mice in the oval $(\mathrm{B} ; 32 \%, \mathrm{t}(15)=3.39, \mathrm{p}=$ $0.004)$, dorsal non-oval $(\mathrm{D} ; 21 \%, \mathrm{t}(15)=2.12, \mathrm{p}=0.051)$, and ventral $(\mathrm{F} ; 28 \%, \mathrm{t}(15)=3.08$, $\mathrm{p}=0.008)$ subregions. 